\title{
TENDÊNCIAS DE EDUCAÇÃO AMBIENTAL EM LIVROS DIDÁTICOS DE CIÊNCIAS ${ }^{1}$
}

\author{
Adriana Silva Mello \\ Marcos Daniel Longhini ${ }^{3}$
}

Resumo: Este artigo evidencia em quais conteúdos curriculares a temática ambiental é discutida identificando as possíveis tendências de Educação Ambiental (EA) presentes em duas coleções de livros didáticos mais adotados em escolas da rede municipal de ensino de Uberlândia, MG, no período de 2008 a 2010. Para a análise da abordagem de ambas as coleções, estabelecemos como parâmetros dois macroeixos que fundamentam o debate da EA: a corrente conservadora e a emancipatória. De modo geral, ambas as coleções, ao discutirem as questões relativas à temática ambiental, ainda tratam as atividades educativas com enfoque informativo, com vistas simplesmente à preservação e conservação da fauna, flora e recursos naturais. Assim, considerando a importância do livro didático e a existência de lacunas quanto à abordagem da EA na ótica da sustentabilidade, registramos a importância da inclusão dessa temática como item eliminatório e classificatório quando da seleção dos livros pelo Programa Nacional do Livro Didático.

Palavras-chave: Livro didático. Ciências. Tendências de Educação Ambiental.

\section{TRENDS IN ENVIRONMENTAL EDUCATION IN SCIENCE TEXTBOOKS}

\begin{abstract}
This paper shows in which curriculum contents the environmental theme is discussed by identifying possible tendencies for Enviromental Education present in two Science textbook collections widely adopted by public schools in Uberlandia, MG. The research was carried out from 2008 to 2010. In order to analyze the theoretical approach of both collections, two macro axes underlying the discussion of Enviromental Education were established: conservative and emancipatory. In general, both collections, when discussing questions relating to the environmental theme, still focus on educational activities under the informational approach, aiming at just the preservation and conservation of flora, fauna and natural resources. Thus, considering the importance of textbooks, combined with the existence of gaps in the approach of environmental education from the sustainability perspective, we note the importance of including this subject as an elimination and ranking criterion for the selection of books for the National Textbook Program.
\end{abstract}

Keywords: Textbooks. Science. Trends in Environmental Education.

\section{TENDENCIAS DE EDUCACIÓN AMBIENTAL EN LIBROS DIDÁCTICOS DE CIENCIAS}

Resumen: Este artículo evidencia en cuáles contenidos curriculares la temática ambiental se discute identificando las posibles tendencias de Educación Ambiental (EA) presentes en las dos colecciones de libros didácticos más adoptados en las escuelas de la red municipal de enseñanza de Uberlândia, MG, en el periodo de 2008 a 2010. Para el análisis del abordaje de ambas colecciones, establecemos como parámetros dos macroejes que fundamentan el debate de la EA:

\footnotetext{
${ }^{1}$ Artigo baseado na dissertação de Mestrado no Programa de Pós Graduação em Educação da Universidade Federal de Uberlândia.

${ }^{2}$ Prefeitura Municipal de Uberlândia -Secretaria Municipal de Educação, Uberlândia, Brasil, drismello@gmail.com

3Professor Adjunto 4 da Faculdade de Educação-FACED,Universidade Federal de Uberlândia(UFU), mdlonguini@yahoo.com.br
} 
la corriente conservadora y la emancipadora. De modo general, ambas colecciones, al discutir las cuestiones relativas a la temática ambiental, aún tratan las actividades educativas con un enfoque informativo, con vistas simplemente a la preservación y conservación de la fauna, flora y recursos naturales. Así, considerando la importancia del libro didáctico y la existencia de lagunas en cuanto al abordaje de la EA en la óptica de la sostenibilidad, registramos la importancia de la inclusión de esta temática como ítem eliminatorio y clasificatorio cuando se hace la selección de los libros por el Programa Nacional del Libro Didáctico.

Palabras clave: Libro didáctico. Ciencias. Tendencias de Educación Ambiental.

É sabido que a preocupação com as questões ambientais surgiu em meio à dinâmica dos movimentos ambientalistas, impelidos pelos irrefreáveis desequilíbrios provocados pelo modelo socioeconômico capitalista, gerador, por um lado, de riquezas e farturas no mundo e, por outro, responsável pela crescente pobreza, pela degradação ambiental e pela poluição. A expressão Educação Ambiental (EA), oriunda do termo Enviromental Education, está muito presente em nosso cotidiano, desde as últimas três décadas do século XX. Todavia, essa expressão, segundo Dias (2003), foi cunhada pela primeira vez no ano de 1965, durante uma Conferência em Educação na Grã-Bretanha.

No decorrer desta pesquisa, verificamos que o conceito da EA varia de acordo com cada contexto. Nada mais imperativo, portanto, do que começar a perceber o seu significado em nível semântico e depois ampliar os conceitos dessa prática, colocando à disposição diferentes definições.

De acordo com o Dicionário Houaiss da Língua Portuguesa (2001), o adjetivo 'ambiental' é um neologismo que apresenta sentidos amplos referentes às condições materiais, socioculturais, psicológicas e morais que formam o conjunto de especificidades do meio histórico, natural ou social. Esse termo busca a formação do sujeito a partir da sua interação com a natureza e outros indivíduos, visto que "possui relações com a mudança social, seja na perspectiva da manutenção do status quo ou na transformação social” (LAYRARGUES, 2009, p. 25).

Ainda segundo esse autor, "o adjetivo ambiental designa uma classe de características que qualificam essa prática educativa, diante desta crise ambiental que ora o mundo vivencia" (LAYRARGUES, 2004, p. 7).

Já o substantivo 'educação' sugere trocas de saberes entre os indivíduos que implicam fazeres pedagógicos indispensáveis à prática docente. Nos dizeres de Freire (2003, p. 98), "a educação é uma forma de intervenção no mundo". Assim, EA é um vocábulo composto que remete ao ambiente e à educação.

Nessa perspectiva, como a escola constitui-se no fio condutor que empreende a reforma intelectual e ética de uma sociedade, ela torna-se propícia à promoção de outra relação junto com e no meio ambiente.

Posto isso, a associação dos termos 'educação' e 'ambiental' favorece o surgimento dos preceitos da EA que vão "além do aprendizado sobre a estrutura e o funcionamento dos sistemas ecológicos, e abrange também a estrutura e funcionamento dos sistemas sociais" (LAYRARGUES, 2009, p. 26). Ainda segundo esse autor:

Educação Ambiental é educação e, como tal, serve ou para manter ou para mudar a realidade, reproduzir ou transformar a sociedade; a educação "ambiental" não só poderia como deveria ser praticada com compromisso "social", pois com ela é possível contribuir com a mudança do quadro de desigualdades no País e no mundo. (LAYRARGUES, 2009, p. 28).

Nessa linha de argumentação, se a EA, implicada no fazer histórico-social, nomeia-se educaşão e ambiental, constitui uma prática educativa, que, junto com outras práticas sociais, tornase importante instrumento de cidadania, envolvendo o homem, a natureza e suas relações (SEGURA, 2001). 
No contexto educacional, lócus desta pesquisa, a Educação Ambiental assume uma perspectiva mais abrangente buscando atender às várias recomendações internacionais para uma interação sustentável com o ambiente. Incorpora os mecanismos propostos para a reforma dos processos educacionais, objetivando a formação e/ou o resgate de valores. Tudo isso faz com que o investimento no contexto escolar tenha um papel formador (OLIVEIRA, 2001).

Nessa perspectiva, são fundamentais a percepção, a participação e a crítica da conjuntura social, acrescidas da reflexão constante da práxis pedagógica.

Jacobi (2003, p. 201) esclarece que "o salto de qualidade do ambientalismo ocorre na medida em que se cria uma identidade crescente entre o significado e dimensões das práticas, com forte ênfase na degradação ambiental e desigualdade social, reforçando a necessidade de alianças e interlocuções coletivas".

Para os autores Lima (2002), Loureiro (2006) e Leff (2007), as questões ambientais devem ser tratadas com criticidade, levando-se em conta as questões socioeconômicas e políticas, abolindo-se o mero recitar da problemática da degradação ambiental.

Com a reforma educacional brasileira, a inclusão da EA nos programas de ensino das escolas, restrita inicialmente ao currículo de algumas disciplinas, "ainda não permite um arranjo flexível para que os professores possam implementar a dimensão ambiental em suas aulas" (SATO, 2004, p. 27). Além disso, pode induzir à falsa ideia de que visa somente aspectos físicos e biológicos.

$\mathrm{O}$ MEC, por meio de $\mathrm{PCN}^{4}$, ao definir as questões relativas ao meio ambiente, reconhece o papel fundamental da escola na formação de cidadãos ativos e responsáveis, resgatando valores essenciais, como a ética, a moral, os direitos humanos e o respeito à vida em geral, assim como as diversidades regionais, culturais e políticas do país. De acordo com Sácristan (2001), o desenvolvimento de atividades com esse enfoque é hoje uma exigência para que a escola cumpra sua função social.

Atualmente, a temática ambiental permeia os conteúdos curriculares de Ciências do ensino fundamental, embora o seu tratamento, na prática, ainda se limite a conteúdos relativos à Ecologia. Essa percepção simplista da EA também é frequentemente reafirmada pela mídia, quando evoca ideias de 'natureza', 'fauna e flora' e 'vida selvagem'.

Não se trata de questionar a validade ou não dos conteúdos propostos, mesmo porque eles permanecem sendo discutidos nas disciplinas de Ciências Naturais/Biologia e Geografia, a partir da conotação técnica, relacionada às concepções biológicas, utilização dos recursos naturais, dinâmica e especificidades dos ecossistemas e mudanças climáticas decorrentes da disposição dos conteúdos da EA nos PCN.

Apesar de ser oportuna, a discussão sobre os conteúdos relativos à área ecológicobiológica torna-se ineficaz para a aquisição de conhecimentos necessários à mudança de atitudes e de valores perante a crise ambiental se não estiver inter-relacionada com questões sociopolíticas e culturais locais (MEDINA, 2000).

A organização de conteúdos em projetos, na perspectiva da transversalidade sugerida pelos PCN, favorece a abordagem interdisciplinar da temática ambiental. O que se deve considerar é que dialogar com as diferentes concepções da EA presentes na dinâmica das salas de aula é outro grande paradigma da Educação, haja vista que "as práticas pedagógicas comprometidas com mudanças contrapõem os mais diversos 'sujeitos', ora considerados nos papéis diferenciados do professor(a) e aluno(a), ora compreendidos na condição de diferentes diante de uma história comum" (REIGOTA, 2003, p. 9).

Superar as lacunas do ensino da EA desafia professores(as) de Ciências e livros didáticos da área a estabelecer conexões entre o conteúdo curricular e o cotidiano, visando a formação de sujeitos socialmente participativos.

\footnotetext{
${ }^{4}$ Inspirada nos documentos das Conferências de Estocolmo (1972), Tbilisi (1977) e Rio (1992); a proposta da
} EA, definida nos PCN, constitui a referência curricular nacional comum ao processo educativo. 
É consenso que os docentes devam preparar-se e ampliar dia a dia seu repertório pedagógico, a fim de "viabilizar uma prática educativa que articule, de forma incisiva, a necessidade de se enfrentar concomitantemente a degradação ambiental e os problemas sociais" (TRISTÃO, 2004, p. 21).

"Todavia, a Educação Ambiental, assim como a própria Educação, ainda continua caminhando lentamente no processo de efetivar mudanças nas atitudes e comportamento humanos em relação ao ambiente" (SATO, 2004, p. 23). De acordo com Guerra e Guimarães (2007, p. 158), "nas instituições escolares, a EA é realizada de modo pontual (datas comemorativas, palestras, etc.) e de forma fragmentada, conteudista, com pequeno envolvimento comunitário".

Quanto ao livro didático, no Brasil, bem como em países desenvolvidos, observa-se que essa ferramenta didática é presença marcante nas atividades educacionais. Devido ao seu papel de portador de dimensões técnico-pedagógicas, enquanto "veículo portador de um sistema de valores, de ideologias, de uma cultura de determinada época e de determinada sociedade" (BITTENCOURT, 2005, p. 302), espera-se que o(a) professor(a) o escolha de forma crítica, consciente e condizente com a realidade de seus educandos para nortear as discussões que propiciem mudanças atitudinais.

Diante da reconhecida importância do livro didático no contexto escolar e da necessidade de oferta de materiais que propiciassem a universalização de um ensino de qualidade, o Fundo Nacional de Desenvolvimento da Educação (FNDE), em parceria com a Secretaria de Educação Básica (SEB) e instituições públicas de ensino superior, avaliam pedagogicamente as obras didáticas para as séries/anos finais do ensino fundamental que atendem aos critérios estabelecidos em edital, elaborando resenhas que compõem o Guia do Livro Didático ${ }^{5}$.

Com o propósito de atender às exigências do Programa Nacional do Livro Didático (PNLD), observa-se crescente preocupação das editoras quanto à correção de erros conceituais, à reestruturação dos livros com atualização de conteúdos, ao lançamento de títulos adequados aos critérios propostos e à suspensão de comercialização de títulos reprovados pela rigorosa avaliação realizada pelo programa. Nesse contexto, as reformas curriculares passaram a exigir que os livros didáticos atendessem aos desafios existentes para a Educação Básica do Brasil.

As coleções de livros didáticos analisadas nesta pesquisa não são diferentes, pois obedecem à evolução das técnicas de fabricação e comercialização da lógica do mercado. Ambas tiveram a preocupação em atender às exigências impostas pelas políticas públicas educacionais do governo federal brasileiro.

Segundo Vasconcelos e Souto (2003), os profissionais da educação e os discentes, consumidores finais dos livros didáticos, constituem-se em meros espectadores nesse processo. O rigor dos critérios eliminatórios e classificatórios de avaliação estabelecidos pelo MEC para aprovar as obras didáticas praticamente define sua escolha.

Essa rigorosa avaliação impõe uma linha metodológica aos autores de livros didáticos, o que leva ao risco de suprimir o poder decisório dos professores e inibir a pluralidade pedagógica. Além disso, esse processo de avaliação dos livros didáticos confronta-se com interesses editoriais que nada têm a ver com as novas orientações para se trabalhar o ensino de Ciências.

É notório que a acentuada profissionalização da indústria editorial a torna o setor mais organizado e apto a pleitear posições de destaque em relação a seus interesses econômicos, dados os eficientes mecanismos de divulgação e marketing. Nessa linha de raciocínio, o livro didático posiciona-se no cruzamento sociocultural da pedagogia e da produção editorial.

Entretanto, muitos livros ainda contemplam a "postura utilitarista, antropocêntrica e finalista" da natureza, valorizando os recursos naturais pela sua utilidade ao homem. De acordo com Fracalanza e Megid Neto (2003, p. 154), "quanto ao conhecimento científico veiculado nos

\footnotetext{
${ }^{5}$ Esse guia é disponibilizado em versão impressa e em versão eletrônica e almeja guiar, orientar, nortear a escolha do livro didático adequado ao contexto da comunidade escolar.
} 
livros didáticos de Ciências, não se nota qualquer mudança substancial nas duas ou três últimas décadas”.

Nesses termos faz-se necessário analisar os principais enfoques sugeridos no campo nas conceituações de educação ambiental, expressos nos livros didáticos, que influem na práxis docente; visto que a questão do livro didático representa o grande desafio para o avanço das aprendizagens em Ciências, no tocante à sua produção e adequação aos contextos da EA.

\section{Tendências de EA}

Em decorrência da sua institucionalização, por meio de leis, decretos, projetos políticopedagógicos e diretrizes curriculares, a EA, desde suas primeiras abordagens, apresentou várias denominações, conceitos e modos de conceber e praticar. Diversas concepções pedagógicas de EA emergiram, disputando hegemonia no campo das formulações teóricas, tanto na política nacional como na Academia.

De acordo com Morales (2009, p. 51), “diante dessas abordagens, pode-se delimitar as diferentes maneiras de conceber e praticar a educação ambiental, sendo estas (re)construídas pelas experiências profissionais, o que resulta em várias identidades socioambientais e políticas que se consolidam nos pensamentos e ações cotidianas".

Ainda segundo a autora,

[...] nesse estabelecimento das práticas, vai-se construindo um contexto plural das educações ambientais, como Ecopedagogia, Educação Ambiental Crítica, Educação Ambiental Transformadora, Educação no Processo de Gestão Ambiental, Alfabetização Ecológica, Educação para as Sociedades Sustentáveis, Educação Ambiental popular, Educação Ambiental Formal, entre outras. (MORALES, 2009, p. 51).

O fato de a EA ter recebido várias definições e ser norteada por várias concepções teórico-metodológicas, acrescidas de uma equivocada interpretação dos PCN, no tocante ao tratamento desse eixo transversal, pode dificultar a operacionalização dos conteúdos relativos à temática ambiental em sala de aula.

Nessa ótica, no âmbito escolar, cada educador ambiental estabelece suas ações, de acordo com suas reflexões pedagógicas, expectativas e/ou concepções. Há os que buscam direcionar suas ações metodológicas e/ou projetos educacionais para além da sensibilização e/ou conscientização de problemas ambientais, mas, infelizmente, tendem a enfatizar a resolução dos problemas socioambientais, a partir da visão meramente funcional da sociedade.

Posto isso, para que haja compreensão do paradigma ecológico, faz-se necessário o conhecimento das tendências de EA que fundamentam a situação atual, a partir da histórica relação homem-natureza.

Neste estudo, toma-se a posição de considerar os dois macroeixos que, em um movimento antagônico, fundamentam o debate da EA, corroborados por Lima (2002) e apontados por Loureiro (2006). São eles: o conservador, também denominado convencional, pragmático, tradicional ou comportamentalista, e o emancipatório, transformador, crítico e ecopedagógico.

A vertente da EA Conservadora, segundo Lima (2002, p. 128-129), caracteriza-se pela:

- Concepção reducionista, fragmentada e unilateral da questão ambiental, dada a sua compreensão naturalista e conservacionista;

- Tendência a sobrevalorizar as respostas tecnológicas diante dos desafios ambientais. Isso é devido à leitura comportamentalista e individualista da Educação e dos problemas ambientais; 
- Abordagem despolitizada da temática ambiental. Isso se deve a uma limitada ou inexistente perspectiva crítica, que propicia a separação entre as dimensões sociais e naturais da problemática ambiental;

- Baixa incorporação de princípios e práticas interdisciplinares;

- Banalização das noções de cidadania e participação, que, na prática, são reduzidas a uma concepção liberal, passiva e disciplinar.

Para Guimarães (2004, p. 26), a denominada EA Conservadora "se alicerça nessa visão de mundo que fragmenta a realidade, simplificando e reduzindo-a, perdendo a riqueza e a diversidade da relação". Torna-se um modelo insatisfatório a ser praticado pela sociedade porque restringe a compreensão da problemática socioambiental, ignorando a complexa relação que se estabelece entre os diversos atores sociais e destes com o meio ambiente. De acordo com Layrargues e Lima (2011, p. 7),

[...] o predomínio de práticas educativas que investiam em crianças nas escolas, em ações individuais e comportamentais no âmbito doméstico e privado, de forma ahistórica, apolítica, conteudística, instrumental e normativa não superariam o paradigma hegemônico que tende a tratar o ser humano como um ente genérico e abstrato, reduzindo os humanos à condição de causadores e vítimas da crise ambiental, desconsiderando qualquer recorte social.

A vertente emancipatória da EA é caracterizada, de acordo com Loureiro (2006, p. 32 33), por apresentar:

- Atitude crítica perante os desafios da crise civilizatória, partindo da compreensão complexa do meio ambiente e do princípio de que o modo como vivemos não atende mais às expectativas e à compreensão de mundo e sociedade;

- Politização da crise ambiental, indissociada de processos como produção-consumo, ética, questões sócio-históricas e dos interesses dos vários segmentos da sociedade;

- Preocupação concreta em estimular o debate e o diálogo entre as ciências, redefinindo objetos de estudo e saberes;

- Entendimento da democracia como condição para a construção de uma sustentabilidade substantiva, ou seja, a negação absoluta dos modelos de desenvolvimento sustentável construídos a partir da primazia do capital sobre a vida;

- Convicção de que o exercício da participação social e da cidadania em sua plenitude é prática indispensável à democracia e à emancipação socioambiental;

- Busca de ruptura e transformação dos valores e práticas sociais contrários à equidade e ao bem-estar público.

Ainda segundo Loureiro (2004, p. 78), “a Educação Ambiental Transformadora procura a realização humana em sociedade enquanto forma de organização coletiva de nossa espécie, e não pela simples 'cópia' de uma natureza descolada do movimento total".

As condições decorrentes da ação humana no ambiente são notoriamente definidas em função de cada modo de vida social em interação com as condições ecológicas de sustentação. Nesse ponto de vista, tomaremos a definição da EA como a práxis educativa fundamentalmente sociocultural, capaz de propiciar a visão holística da realidade que viabiliza a sustentabilidade e, potencialmente, capaz de alavancar mudanças de atitudes e valores que propiciam a superação da atual crise socioambiental. É necessário esclarecer que "a noção de sustentabilidade implica uma dimensão política, social, cultural e biológica e que exige uma extensiva produção e difusão de conhecimentos e de princípios ético-políticos nos espaços das práticas sociais cotidianas" (REIGOTA, 2007, p. 222).

Assim, sem a utopia de propor um modelo educacional para a abordagem ambiental ou de apresentar soluções para os graves problemas ambientais, cabe-nos refletir sobre qual é a nossa contribuição, como profissionais da área de Ciências, para o processo ético de auto- 
organização e para a qualidade de vida no planeta, a partir do momento da escolha do livro didático.

\section{Considerações Metodológicas}

Nos limites deste texto, com o propósito de evidenciar em quais conteúdos curriculares a temática ambiental é discutida, pretende-se focar a abordagem ambiental presente em duas coleções de livros didáticos mais adotados em escolas da rede municipal de ensino de Uberlândia, MG, no período de 2008-2010, identificando as possíveis tendências de Educação Ambiental (EA).

A pesquisa foi realizada em duas etapas: a primeira contempla a descrição das coleções de

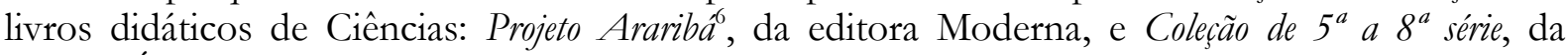
editora Ática. Com base na análise de cada coleção de livros didáticos, foram tecidas correlações entre a concordância ou não das concepções/tendências referentes à EA, explícitas e/ou implícitas nos livros didáticos, com as atuais tendências (macroeixos), a fim de responder à questão central desta pesquisa.

Para a avaliação da abordagem teórica de ambas as coleções de livros didáticos, foram estabelecidos como parâmetros os dois macroeixos, sugeridos por Loureiro (2006) e corroborados por Lima (2002) e Guimarães (2004), que fundamentam o debate da EA: a corrente conservadora e a emancipatória, cujas principais ideias se encontram sistematizadas no Quadro 1.

Quadro 1. Parâmetros utilizados para a análise dos livros didáticos adotados pela rede municipal de ensino de Uberlândia, MG.

\begin{tabular}{|l|l|ll|}
\hline \multicolumn{1}{|c|}{ Parâmetros } & \multicolumn{1}{c|}{ Conservadora } & \multicolumn{1}{c|}{ Emancipatória } \\
\cline { 2 - 5 } & $\begin{array}{l}\text { Antropocêntrica } \\
\text { Reducionista } \\
\text { Fragmentada }\end{array}$ & $\begin{array}{l}\text { Holística, favorecendo a percepção integrada } \\
\text { do meio ambiente }\end{array}$ \\
\hline Abordagem & $\begin{array}{l}\text { Despolitizada } \\
\text { Acrítica }\end{array}$ & $\begin{array}{l}\text { Eticamente politizada } \\
\text { Crítica }\end{array}$ & \\
\hline Discurso & Discurso utilitarista & $\begin{array}{l}\text { Dialogicidade do discurso, visando a a } \\
\text { interdisciplinaridade }\end{array}$ \\
\hline $\begin{array}{l}\text { Ótica } \\
\text { desenvolvimento }\end{array}$ & Insustentabilidade & Sustentabilidade & \\
\hline
\end{tabular}

Fonte: adaptação dos parâmetros das tendências da EA sugeridas por Loureiro (2006).

Ao analisarmos as tendências da EA presentes em ambas as coleções de livros didáticos, adotadas pela rede municipal de ensino de Uberlândia, optamos por desconsiderar a existência de prováveis desatualizações e/ou erros conceituais, eximindo capítulos que não se referem à temática ambiental.

As evidências dessa temática, constatadas em expressões, figuras/ilustrações e atividades, foram assinaladas por chaves e classificadas de acordo com a tendência conservadora ou emancipatória da EA.

Cumpre-nos destacar que não estamos contestando a qualidade das coleções analisadas, as quais estão sintonizadas com as prerrogativas apontadas pelo PNLD/2008.

\section{Discussão e Resultados}

\footnotetext{
${ }^{6}$ Trata-se de uma obra coletiva, concebida e produzida pela editora Moderna.
} 
Nos oito volumes das coleções analisadas, os conteúdos programáticos distribuem-se em capítulos, apresentando textos científicos entremeados de ilustrações, seguidos por atividades que não fogem aos padrões dos livros didáticos.

De modo geral, ambas as coleções de livros didáticos recomendadas pelo PNLD/2008 distribuem os conteúdos programáticos por capítulos entremeados de ilustrações e sugestões de atividades.

No "Suplemento do professor", verificamos a existência de sugestões de filmes, sites, jogos e livros relacionados às questões ambientais, além de textos complementares e atividades adicionais que subsidiam a tarefa do docente.

A coleção didática do Projeto Araribá não apresenta estereótipos ou associações que desvalorizem grupos étnico-raciais ou desmereçam a contribuição de segmentos da comunidade; também incentiva uma postura de preservação e conservação, enfocando a importância da sustentabilidade para a melhoria da qualidade de vida de toda a população. As discussões, em geral, enfatizam o exercício da cidadania e o cuidado com a saúde e o meio ambiente.

Numa análise quantitativa, verificamos que, dos 198 capítulos que compõem os quatro volumes da coleção do Projeto Araribá, apenas 46 capítulos trazem enunciados, figuras, atividades, seções e/ou textos complementares que remetem à temática ambiental.

Esses capítulos, distribuídos nos volumes da $5^{\mathrm{a}}, 6^{\mathrm{a}}$ e $8^{\mathrm{a}}$ séries, cujas áreas de concentração referem-se, respectivamente, às Ciências da Terra, Ecologia e Noções de Química, Física e Tecnologia da Informação e Comunicação (TIC), totalizam um percentual baixo (28,88\%), se considerarmos o conhecimento hoje disponível relativo à crise ambiental global e à relação direta dessas áreas de conhecimento com questões cotidianas.

Verificamos que, majoritariamente, os conteúdos estão sintonizados com o reconhecimento das relações sociopolítico-culturais como precursoras da crise socioambiental contemporânea, posicionando-se na direção da EA emancipatória sugerida por Loureiro (2006), como ilustra o Fragmento 1.

A saúde e a sociedade

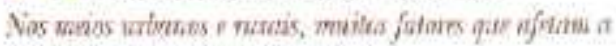

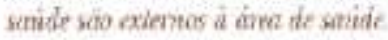

\section{Saúde e desenvolvimento}

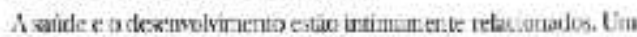

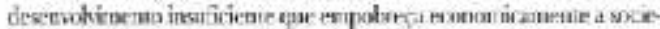

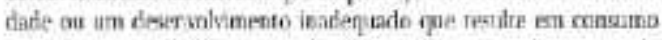

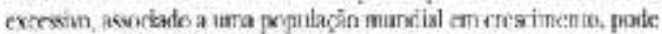

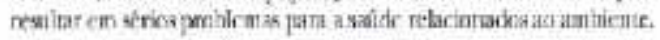

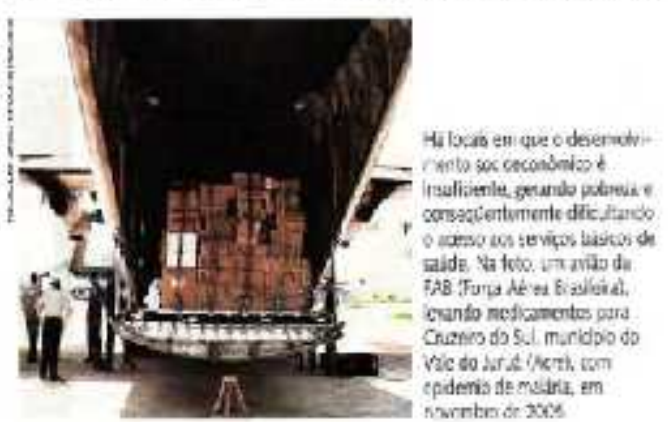

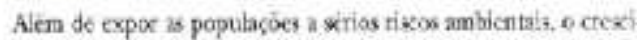

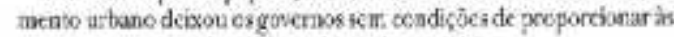
pessuas as ser vicyas de saide ambiental aecestair:os.

A poiniçào amhiertal das ástas urhanas $c$ runis pstâ associuta a

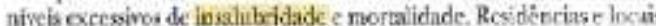

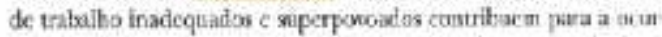

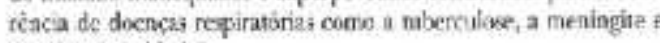
cutras eniermidades

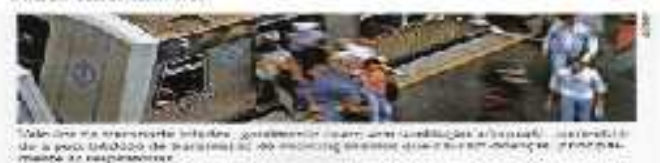

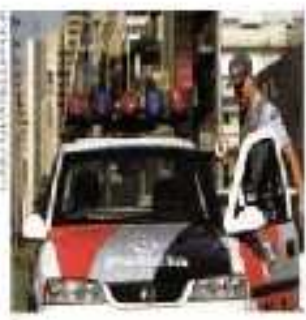

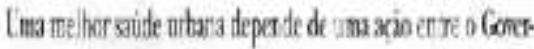

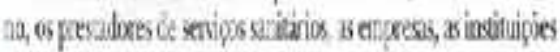

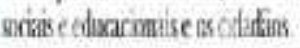

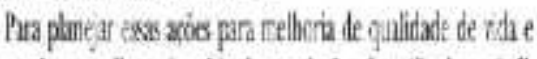

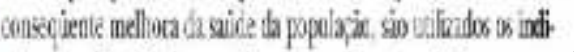

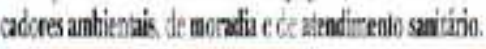

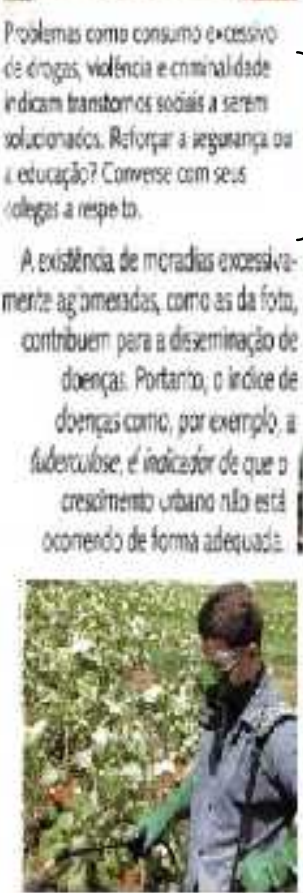

Nem todos os trabalhadores têm acesso aos equipamentos de proteçấo individual, o que aumenta os indices de acidentes no trabalho e nos transportes, indicando falhas na prevengão de acidentes. 
Fragmento 1. Reprodução das páginas 90-91. Projeto Araribá, 2006, $7^{\mathrm{a}}$ série.

Conforme pudemos verificar nos trechos assinalados dessas páginas espelhadas do capítulo 4, a influência dos indicadores ambientais de moradia e atendimento sanitário na saúde humana e a relação entre saúde e desenvolvimento socioeconômico foram ressaltadas. $\mathrm{O}$ conteúdo sinaliza o reconhecimento das relações sociopolítica e econômica como precursoras da crise socioambiental contemporânea. Já as imagens contemplam situações cotidianas, tais como questões relativas à saúde e ao desenvolvimento socioeconômico, que propiciam o debate entre a temática ambiental em um contexto holístico. Todavia, a discussão da questão ambiental, com foco no contexto sociopolítico-cultural sustentável, que favoreça a reflexão e o posicionamento do(a) educando(a) e propicie o estabelecimento do compromisso social, como previsto na prática da EA emancipatória, não se efetuará sem o encaminhamento didático do(a) educador(a).

Nessa linha de raciocínio, Layrargues (2001, p. 133) argumenta que

[...] uma aproximação do vínculo entre os processos educativos e a realidade cotidiana dos educandos, onde a ação local representa a melhor oportunidade tanto do enfrentamento dos problemas ambientais como da compreensão da complexa interação dos aspectos ecológicos com os político-econômicos e socioculturais da questão ambiental.

No apontamento do Fragmento 2, percebemos a ênfase no domínio humano sobre os recursos naturais, reproduzindo-se, assim, o senso comum de culpabilização do homem pela degradação dos recursos naturais (no caso, o solo). Isso privilegia uma concepção utilitarista dos recursos naturais (antropocentrismo), característica da tendência conservadora da EA.

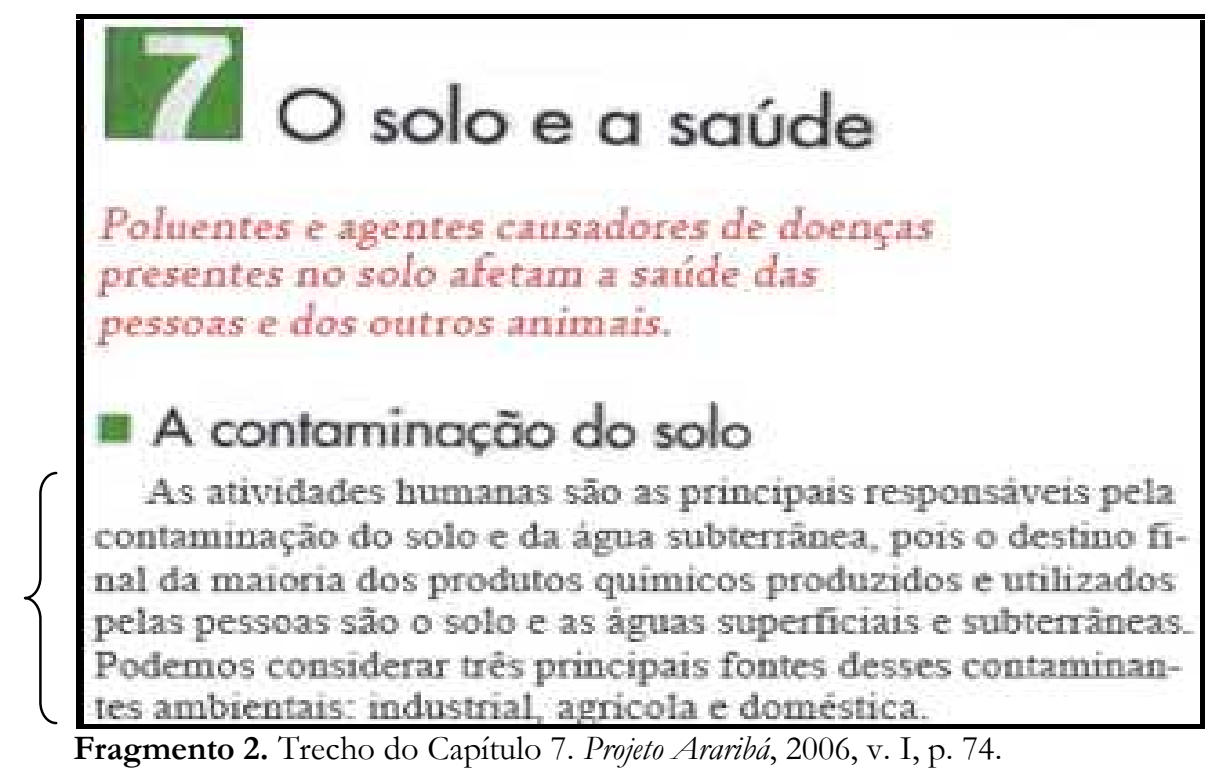

De modo geral, verifica-se uma mescla de trechos, inseridos no corpo textual dos volumes da coleção Projeto Araribá, que encaminham para a perspectiva crítica a politização da crise ambiental, mas eles exigem a intervenção do professor para serem evidenciados, quando do tratamento dos conteúdos.

De acordo com o Guia Curricular-PNLD/2008, a Coleção Ciências, do autor Fernando Gewandsznajder, aborda os conteúdos em nível apropriado, usando linguagem adequada para tal. A coleção apresenta boa diagramação e figuras de qualidade, embora seja necessária a atenção do 
professor a fim de evitar interpretações imprecisas. Ainda segundo o Guia Curricular PNLD/2008, nessa coleção verifica-se uma preocupação quanto à conservação e manejo correto do meio ambiente.

A coleção relaciona a ciência com o desenvolvimento e o bem-estar social, apresentando conceitos conectados com situações práticas das diversas áreas do conhecimento e com as teorias atuais do ensino de Ciências.

Contudo, a partir dos dados obtidos e das análises realizadas, concluímos que o desenvolvimento dos conteúdos programáticos da Coleção Ciências mantém estreita relação com uma EA conservadora, pois se restringe a abordagens comportamentalista-individualistas, com vistas ao indivíduo transformado.

Nos volumes da $5^{\mathrm{a}}, 6^{\mathrm{a}}$ e $8^{\mathrm{a}}$ séries dessa coleção, o percentual de capítulos que se referem à temática ambiental totaliza $26,02 \%$, atingindo maior percentual no volume da $5^{\text {a }}$ série $(47,61 \%)$. Esses capítulos tratam de "O que a Ecologia estuda", "Teia alimentar", "O solo e a saúde do corpo", "O lixo", "Nossos recursos naturais", "Os estados físicos da água", "A qualidade da água", "A água e a nossa saúde", "De que é feito o ar" e "O ar e a nossa saúde".

Apesar das escassas discussões sobre EA em um volume que, teoricamente, deveria tratar mais diretamente a questão, os conteúdos que cogitam a temática ambiental apresentam-se de forma superficial, fragmentada, com ênfase na resolução de problemas.

Outras discussões sobre a problemática ambiental, abordadas nas demais séries do ensino fundamental da educação básica, correspondem às relações entre saúde e ambiente, à descrição de doenças e transformações químicas e físicas.

Embora fosse oportuna a correlação entre o conteúdo programático, especialmente da área de Química com a EA, a dinâmica da discussão sobre EA no volume da $8^{a}$ série da Coleção Ciências tem caráter formativo e descritivo, referente às noções de Química e Física. Esse enfoque ligado a uma dimensão técnica não foge à regra da maioria dos livros didáticos, tal como aponta Bizzo (2002), e pouco ou quase não propicia mudanças de atitudes e valores, tampouco a participação social.

Quanto às possíveis vinculações dessa coleção com a temática ambiental, constatamos a estreita relação com uma EA Conservadora (devido aos aspectos do tipo comportamentalistaindividualista, observados ao longo dos conteúdos programáticos) com nuances da EA emancipatória, perceptíveis ao olhar crítico do (a) docente.

Para representar a coleção, tomamos como exemplo o trecho "Ciência e Ambiente" (Fragmento 3), que ilustra o enfoque meramente informativo da questão ambiental, voltado para o conhecimento retido com vistas ao indivíduo transformado.

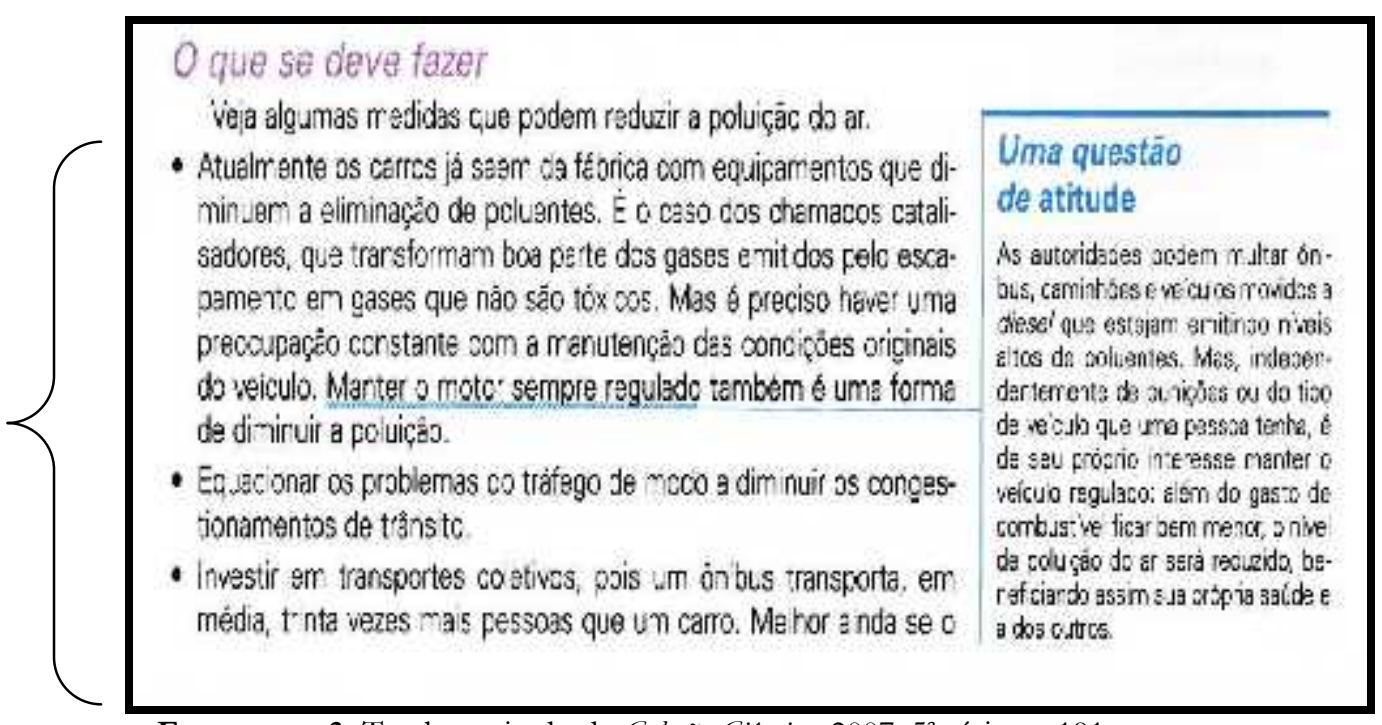

Fragmento 3. Trecho retirado da Coleção Ciências, 2007, 5ª série, p. 191. 
A discussão informativa e isolada da problemática ambiental desse fragmento molda-se aos princípios e particularidades da tendência conservadora da EA, além de reforçar a culpabilidade do desenvolvimento econômico.

É sabido que a mera enumeração de "medidas de redução de poluição", "dicas de economia" e "reaproveitamento de material reciclável", isolada da discussão reflexiva sobre o modelo atual de economia e do envolvimento dos atores sociais, pouco contribui para a mudança de atitudes em relação ao ambiente, pois não encaminha para a reflexão sobre os hábitos que decorrem do modelo capitalista da sociedade nem identifica os atores sociais envolvidos.

Afinal, a formação de hábitos educativos para a preservação e conservação do meio em que vivemos se dá "a partir da visão globalizada do tema, perpassando as diversas áreas do conhecimento com vistas à Agenda 21" (MELLO; MONTES; LIMA, 2009, p. 55).

onsiderando-se os resultados obtidos da análise das coleções de livros didáticos de Ciências, o Gráfico 1 evidencia o percentual de capítulos que remetem à temática ambiental.
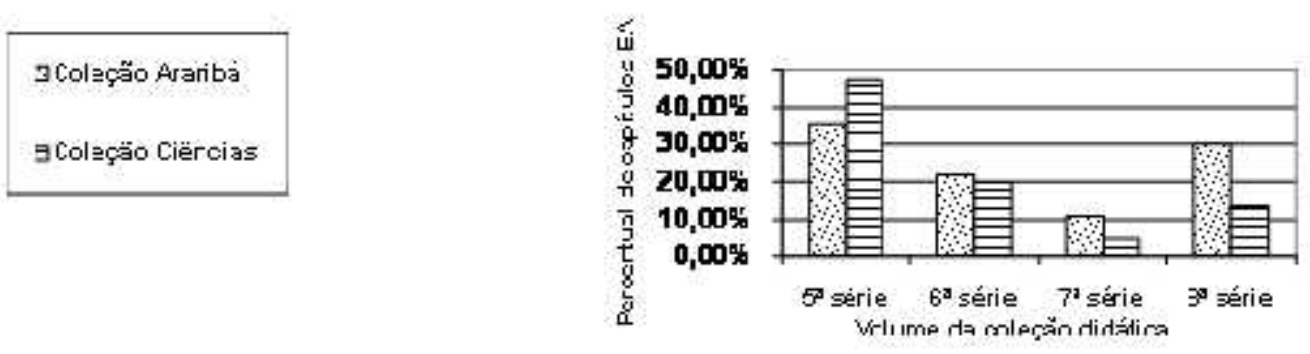

Gráfico 1. Percentual de capítulos que abordam EA.

Os resultados desta pesquisa indicam que os conteúdos curriculares discutidos na $5^{\mathrm{a}}, 6^{\mathrm{a}} \mathrm{e}$ $8^{a}$ séries viabilizam o tratamento de questões relativas à temática ambiental pelo fato de, nessas séries, respectivamente, tratar do estudo dos ambientes, seres vivos e noções básicas de Química.

Nos volumes da $7^{a}$ série ( $8^{\circ}$ ano) de ambas as coleções, a discussão sobre as questões ambientais são escassas, provavelmente, por o foco ser a anatomia e fisiologia humana.

No volume da $8^{a}$ série, observamos que a discussão sobre os conteúdos de Química não se alicerça em sua visão ampla de meio ambiente, incluindo seus aspectos sociais em direção ao desenvolvimento de atitudes que visam suprimir a ênfase do desenvolvimento de atitudes conservacionistas pela ótica da sustentabilidade socioambiental.

Apesar de a organização de conteúdos em projetos, na perspectiva da transversalidade sugerida pelos PCN, favorecer a abordagem interdisciplinar da temática ambiental, o que se deve considerar é que dialogar com as diferentes concepções da EA presentes na dinâmica das salas de aula é outro grande desafio da Educação, haja vista que "as práticas pedagógicas comprometidas com mudanças contrapõem os mais diversos 'sujeitos', ora considerados nos papéis diferenciados do professor (a) e aluno(a), ora compreendidos na condição de diferentes diante de uma história comum" (REIGOTA, 2004, p. 9).

Além disso, as recomendações dos princípios ambientais emancipatórios não se baseiam exclusivamente na sensibilização acerca da crise ambiental, que acarreta uma visão simplista e acrítica da problemática ambiental; ressaltamos a necessidade de o processo educativo ser orientado para a sustentabilidade socioambiental, na linha de intervenções coletivas em prol do meio ambiente.

Apesar de parecer utópico, em longo prazo isso pode ser atingido por meio de enfoques interdisciplinares e de participação ativa e responsável de cada indivíduo e da coletividade, respeitando as singularidades dos diferentes conteúdos curriculares. 
Nessa perspectiva, os educadores exercem o papel-chave para que o estudo da EA propicie o desenvolvimento da criticidade dos educandos, o seu posicionamento perante as questões ambientais, capaz de provocar mudanças de comportamentos.

Por outro lado, as modificações no processo educacional precisam considerar a cultura arraigada dos educadores em lidar com a fragmentação dos conteúdos relacionados à temática ambiental e à organização do tempo nas escolas.

Embora o PNLD disponibilize, no mercado editorial, coleções de obras didáticas de melhor qualidade, verificamos que, no tocante à $\mathrm{EA}$, ainda não há determinação para que seu tratamento esteja em conformidade com os princípios da EA emancipatória.

De modo geral, ambas as coleções de livros didáticos ainda contêm abordagens superficiais sobre a temática com vistas à preservação e conservação da fauna, flora e recursos naturais, sinalizando algumas particularidades e singularidades de EA emancipatória.

Acreditamos que discussões com o enfoque dos efeitos, das consequências, e não propriamente das causas dos problemas, eximindo a responsabilidade dos diversos atores sociais envolvidos, pouco contribuem para a análise crítico-reflexiva da questão ambiental e para mudanças de atitudes para com o meio ambiente.

Esse fato serve de alerta para os(as) educadores(as) dispostos(as) a discutir sobre a EA, quando da análise dos livros didáticos aprovados pelo PNLD. Assim, sem a utopia de propor modelo educacional para a abordagem ambiental ou de apresentar soluções para os graves problemas ambientais, cabe-nos refletir, à guisa de conclusões, sobre qual é a nossa contribuição, como profissionais da Educação, para o processo ético de auto-organização e para a qualidade de vida no planeta, a partir do momento da escolha do livro didático de Ciências.

Posto isso, é importante salientar que não existe livro melhor ou pior; afinal, o valor textual e a decisão de como usar criticamente uma coleção didática são determinados pelo profissional da Educação.

Assim, considerando a repercussão que os livros didáticos têm sobre os educandos, aliada ao fato de o livro didático representar o grande desafio para o avanço das aprendizagens em Ciências, no tocante à sua produção e adequação aos contextos da EA, registramos a importância da inclusão dessa temática, como item eliminatório e classificatório, quando da seleção dos livros para o PNLD para a efetivação do ensino da EA na ótica da sustentabilidade no âmbito escolar.

\section{Referências}

BITTENCOURT, Circe Maria F. Ensino de História: fundamentos e métodos. São Paulo: Cortez, 2005.

BIZZO, Nelio. A avaliação oficial de materiais didáticos de Ciências para o ensino fundamental no Brasil. In: ENCONTRO PERSPECTIVAS DO ENSINO DE BIOLOGIA, 7.. 2000, São Paulo. Anais... São Paulo: 2000. p. 54-58.

$$
\text { Ciência fácil ou difícil? 2. ed. São Paulo: Ática, } 2002 .
$$

BRASIL. Ministério de Educação e Cultura. Parâmetros Curriculares Nacionais $-5^{\mathrm{a}}$ a $8^{\mathrm{a}}$ série. Secretaria da Educação Fundamental. Brasília, DF: MEC/SEF, 1998. (v. 1).

Ministério da Educação. Guia de livros didáticos PNLD 2008: Ciências/Ministério da Educação. Brasília, DF: MEC, 2007.

DIAS, Genebaldo Freire. Educação ambiental: princípios e práticas. 8. ed. São Paulo: Gaia, 2003.

FRACALANZA, Hilário; MEGID NETO, Jorge. O livro didático de Ciências: problemas e soluções. Ciências \& Educação, v. 9, n. 2, p. 147-157, 2003. 
FREIRE, Paulo. Pedagogia do oprimido. 35. ed. Rio de Janeiro: Paz e Terra, 2003.

GEWANDSZNAJDER, Fernando. Coleção de Ciências de $5^{a}$ a $8^{a}$ séries. 3. ed. São Paulo: Ática, 2007.

GUERRA, Antonio Fernando S.; GUIMARÃES, Mauro. Educação Ambiental no contexto escolar: questões levantadas no GDP. Pesquisa em Educação Ambiental, v. 2, n. 1, p. 155-166, 2007.

GUIMARÃES, Mauro. Educação Ambiental Crítica. In: LAYRARGUES, Philippe Pomier (Coord.). Identidades da educaşão ambiental brasileira. Brasília: Ministério do Meio Ambiente, 2004. p. 25-34.

HOUAIS, Antônio; VILLAR, Mauro de Salles. Dicionário Honaiss da Lingua Portuguesa. Rio de Janeiro: Objetiva, 2001.

JACOBI, Pedro. Educação ambiental, cidadania e sustentabilidade. Cadernos de Pesquisa, n. 118, mar. 2003. Disponível em: <http://www.scielo.br/pdf/cp/n118/16834.pdf>. Acesso em: 01 dez. 2008.

LAYRARGUES, Philippe Pomier. A resolução de problemas ambientais locais deve ser tema gerador ou atividade fim da educação ambiental? In: REIGOTA, Marcos. Verde cotidiano: o meio ambiente em discussão. 2. ed. Rio de Janeiro: DP\&A, 2001.

- (Re)conhecendo a educação ambiental brasileira. In: Identidades da educação ambiental brasileira. Brasília: Ministério do Meio Ambiente, 2004.

Educação ambiental com compromisso social: o desafio da superação das desigualdades. In: LOUREIRO, Carlos Frederico Bernardo; LAYRARGUES, Philippe Pomier; CASTRO, Ronaldo Souza de (Org.). Repensar a educação ambiental: um olhar crítico. São Paulo: Cortez, 2009. p. 11-31.

LAYRARGUES, Philippe Pomier; LIMA, Gustavo Ferreira da Costa. Mapeando as macrotendências político-pedagógicas da educação ambiental contemporânea no Brasil. In: ENCONTRO DE PESQUISA EM EDUCAÇÃO AMBIENTAL, 6., 2011, Ribeirão Preto. Anais... Ribeirão Preto: USP, 2011. v. 6. p. 01-15.

LEFF, Enrique. Saber ambiental: sustentabilidade, racionalidade, complexidade, poder. Tradução de Lúcia Mathilde Endlich Orth. Petrópolis, RJ: Vozes, 2007.

LIMA, Gustavo Ferreira da Costa. Crise ambiental, educação e cidadania: os desafios da sustentabilidade emancipatória. In: LOUREIRO, Carlos Frederico Bernardo (Org.). Educação ambiental: repensando o espaço da cidadania. São Paulo: Cortez, 2002.

LOUREIRO, Carlos Frederico Bernardo. Educação ambiental transformadora. In: LAYRARGUES, Philippe Pomier (Coord.). Identidades da educaşão ambiental brasileira. Brasília: Ministério do Meio Ambiente, 2004. p. 65-84.

Trajetória e fundamentos da educação ambiental. 2. ed. São Paulo: Cortez, 2006.

2007.

Epistemologia ambiental. Tradução de Sandra Valenzuela. 4. ed. revista. São Paulo: Cortez, 
MEDINA, Naná Mininni. Textos sobre capacitação de professores em educação ambiental. In: BRASIL. Ministério de Educação. Secretaria de Educação Fundamental. Departamento de Política da Educação Fundamental. Oficina panorama de educação ambiental no Brasil. [s.1], 2000.

MELLO, Adriana Silva; MONTES, Silma Rabelo; LIMA, Luís de. Educação Ambiental em curso de formação continuada para docentes do ensino básico. Em extensão, Uberlândia, v. 8, n. 1. p. 4859, jan./jul. 2009.

MORALES, Angélica Góis. A formação do profissional educador ambiental: reflexões, possibilidades e constatações. Ponta Grossa: UEPG, 2009.

OLIVEIRA, Mirna Gertrudes Ribeiro. Educação ambiental na base do ensino: uma análise do real e a construção de uma convivência ecológica na escola. 2001. Dissertação (Mestrado em Geografia) - Programa de Pós-Graduação em Geografia, Universidade Federal de Uberlândia, Uberlândia, MG, 2001.

PROJETO ARARIBÁ. Coleção de $5^{a}$ a $8^{a}$ série/Ensino Fundamental. São Paulo: Moderna, 2006.

REIGOTA, Marcos. Meio ambiente e representação social. 7. ed. São Paulo: Cortez, 2007.

SATO, Michèle. Educação ambiental. São Carlos, SP: Rima, 2004.

SÁCRISTAN, José Gimeno. A educação obrigatória: seu sentido educativo e social. Porto Alegre: Artmed, 2001.

SEGURA, Denise de Souza Baena. Educação ambiental ingênua à consciência crítica. São Paulo: Annablume, FAPESP, 2001.

TRISTÃO, Martha. A educação ambiental na formação de professores: redes de saberes. São Paulo: Annablume; Vitória: Facitec, 2004.

VASCONCELOS, Simão Dias; SOUTO, Emanuel. O livro didático de Ciências no ensino fundamental - proposta de critérios para análise do conteúdo zoológico. Ciência \& Educação, v. 9, n. 1, p. 93-104, 2003.

Artigo recebido em 26/06/2011

Artigo aprovado em 05/09/2012 